\title{
Severe Guillain-Barré syndrome following urethritis with cardiovascular and ophthalmic involvement
}

\author{
A. J. Marshall \\ M.B., M.R.C.P.
}

\author{
F. Elizabeth Rogerson \\ M.B., B.S.
}

Royal Devon and Exeter Hospitals, Exeter, Devon

\begin{abstract}
Summary
A patient with a severe form of the Guillain-Barré syndrome is described and the case illustrates the rare cardiovascular and ophthalmic complications which can occur. Urethritis, probably due to gonorrhoea, preceded neurological symptoms and this association has not been previously reported.
\end{abstract}

\section{Introduction}

In 1916, Guillain, Barré and Strohl described acute polyneuritis presenting with muscle weakness and parasthesiae, with or without premonitory symptoms and leading to flaccid paralysis and areflexia. The cerebrospinal fluid protein concentration was raised but there was no excess of cells (dissociation albumino-cytologique). There have been many reported cases since, and it is well known that involvement of the spinal nerves commonly necessitates artificial ventilation and intensive supportive care. Less well recognized are the equally serious changes which may occur in the cranial nerves and cardiovascular system.

The pathogenesis of the Guillain-Barré syndrome, also called acute infective polyneuritis, is not yet elucidated. It has followed a variety of infectious illnesses including herpes zoster, echovirus 7 and 9, measles, infectious mononucleosis, Mycoplasma pneumoniae infection and salmonellosis. Other cases have been associated with non-infective disease such as malignancy, chronic lymphatic leukaemia, ingestion of drugs and toxins and surgical operations. As no one aetiological factor has been found it may be that a hypersensitivity reaction is involved in the initiation of the illness.

\section{Case report}

A 23-year-old landscape gardener developed dysuria, frequency, and a purulent urethral discharge 1 week after sexual intercourse. The symptoms were associated with a mild constitutional disturbance but were ignored because of reassurance from a friend with a similar complaint. Three weeks later he noticed backache, neck stiffness and parasthesiae or in his hands, feet and tongue and after 4 days was $\vec{i}$ admitted to hospital with progressive weakness of $\bullet$ his arms and legs.

On examination, loss of power was most marked $\stackrel{\oplus}{\omega}$ in the trunk and proximal limb muscles, all tendon 음 reflexes were absent, and there were minimal peri- $\rightarrow$ pheral sensory changes. He was able to walk only by $\underset{\mathcal{D}}{\mathcal{D}}$ supporting himself on surrounding furniture. The cerebrospinal fluid pressure was $140 \mathrm{~mm}$ of water $\stackrel{D}{\exists}$ the protein was $96 \mathrm{mg} / 100 \mathrm{ml}$ and there were no white cells present. Culture for viruses from the blood, faeces and throat swabs, a Paul Bunnel tesi $\vec{\varphi}$ and agglutination tests for salmonellosis and or brucellosis were negative.

The Guillain-Barré syndrome was diagnosed and treatment started with prednisone $60 \mathrm{mg}$ daily. A presumptive diagnosis of gonorrhoea was made when Gram-negative diplococci and pus cells were seen in $\mathbb{8}$ the urethral discharge. $1.2 \mathrm{Mu}$ of procaine penicillin were given intramuscularly on 2 successive days after which the discharge and dysuria ceased.

Muscle paralysis increased and 6 days after admission the patient developed cranial nerve involvement with a marked left facial weakness and difficulty in coughing and swallowing. Respiratory function deteriorated until after 8 days, when the minute volume was 121 and vital capacity 1.81 , a tracheostomy was performed and he was ventilated. He became completely paralysed apart from some 음 slight movement of the head and neck. During 9 days when he was constantly ventilated, muscle power began to return in the trunk and upper limbs but intermittent mechanical ventilation was necessary $\sigma$ for a further 28 days. Reduced pain, touch, vibration and proprioceptive sensations were demonstrated in the distal parts of the limbs but sphincter control remained intact throughout the illness.

The electrocardiogram 4 days after admission was normal. However, the heart rate gradually increased $\stackrel{0}{?}$ and 7 days after admission and before ventilation, 7 was 150 beats/min. Marked T wave inversion was 


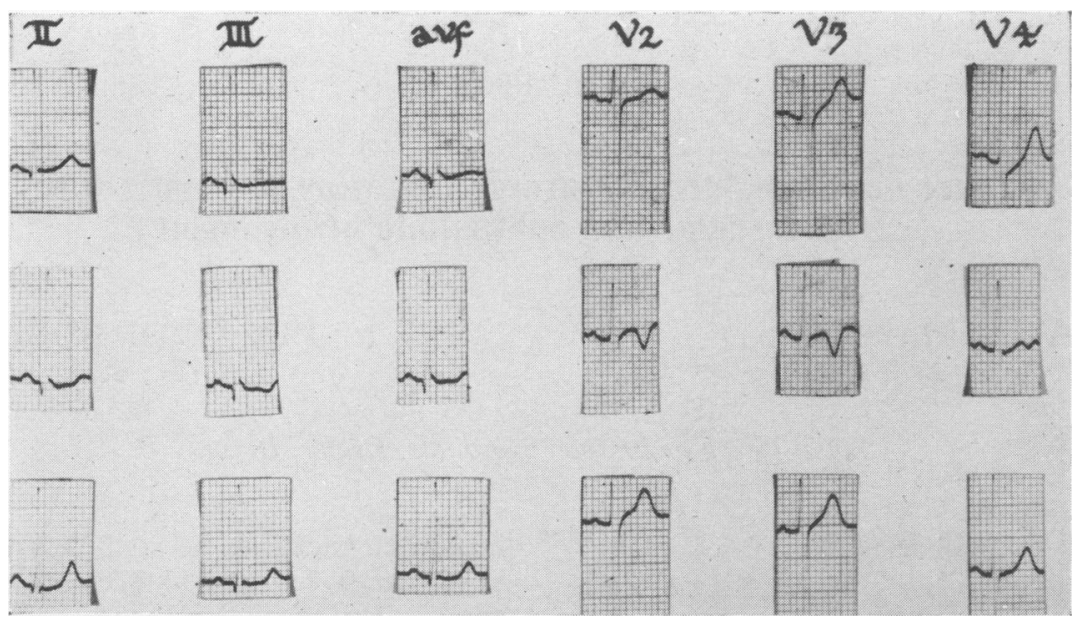

Fig. 1. Electrocardiograms 4 days, 10 days and 4 months after admission.

present in electrocardiogram limb leads II, III, VR, VF and chest leads 1-3 (Fig. 1). Decrease in the heart rate did not occur for 5 weeks, but after another 2 months the rate was normal. When electrocardiographic changes were greatest the serum aspartate aminotransferase was elevated to $144 \mathrm{mu} / \mathrm{ml}$ (normal 10-50) and lactic dehydrogenase $600 \mathrm{mu} / \mathrm{ml}$ (normal, 90-220). His blood pressure was initially $120 / 80$ $\mathrm{mmHg}$, but rose to $150 / 100 \mathrm{mmHg} 10$ days after admission. Hypertension with pressure recordings of $210 / 110 \mathrm{mmHg}$ persisted for 4 weeks. It settled at $105 / 50 \mathrm{mmHg}$ after complete recovery.

The maximum involvement of the cardiovascular and motor systems coincided but at the time when these changes were regressing the patient complained of diplopia. He was unable to abduct either eye from the mid-line and at rest his eyes were convergent with bilateral sixth nerve palsies which remained for 23 days. Bilateral papilloedema with haemorrhages around the discs developed. Visual acuity was right eye $6 / 12$, left eye $6 / 9$ and blurring of vision prevented him from reading or watching television. This symptom slowly improved over 22 days and fundal changes completely regressed. Visual acuity was then right eye $6 / 4$, left eye $6 / 4$.

When neurological involvement was most extensive the erythrocyte sedimentation rate was $83 \mathrm{~mm} / \mathrm{hr}$ (Westergren), but this fell to $14 \mathrm{~mm} / \mathrm{hr}$ as recovery progressed. Anti-nuclear factor was present in the blood in concentration 1 in 40 for 3 months but was not detected later.

Prednisone, which was started on the day of admission, was gradually reduced over a period of 7 weeks. Although tendon reflexes have not returned, power was completely normal 8 months after the onset of the illness. The patient has been able to return to full activity and a normal life.

\section{Discussion}

Cardiovascular involvement may lead to death ino̊ the Guillain-Barré syndrome. This is usually the result of peripheral circulatory failure with hypoto tension (Clarke, Bayliss and Cooper, 1954) but? hypertension has also occasionally been reported (Haymaker and Kernohan, 1949). This has been thought to result from anoxia and carbon dioxide retention. However, this patient's blood pressure was persistently raised during and after ventilation when blood gases were shown to be normal. Sinus tachycardia was also a marked feature in this case and although this is common in polyneuritis actual myocardial involvement is known to be rare (Haymaker and Kernohan, 1949). Pathological studies have previously been described (Sabin and Aring, 1941) which showed necrosis and infiltration of cardiac muscle fibres with mononuclear and polymorphonuclear cells and the electrocardiographic changes and elevation of cardiac enzymes suggest that our patient had myocarditis. The precise mechanism for the disturbances of the cardiovascular system observed remain uncertain. The maximal hypertension, tachycardia, cardiac enzyme and electrographic changes were coincident with the peak of neurological signs. It is therefore possible that they result from damage to the autonomic nerves or involvement of the brain stem by a process similar to that occurring in the spinal nerves.

Papilloedema is another rare complication of the syndrome and was not present in any of ninety-seven patients described from the Mayo clinic (Wieder- 
holt, Mulder and Lambert, 1964). In the few previously reported cases with papilloedema there was a higher incidence of cranial nerve palsies (Morley and Reynolds, 1966). We confirm this association and it seems probable that papilloedema was due to actual involvement of the optic nerve-optic neuritis. Other authors have disputed this because visual impairment is extremely uncommon but in this patient some reduction of visual acuity occurred. Other possible causes of papilloedema are impairment of absorption of cerebrospinal fluid due to protein occlusion of the arachnoid villi or raised intracranial pressure, but in this case neither seems likely as the protein level was not grossly elevated and cerebrospinal fluid pressure was normal. Respiratory inadequacy has not usually been associated with papilloedema in previous cases (Morley and Reynolds, 1966) and it is of interest that ophthalmic changes developed here at the time when respiratory function was improving.

Urethritis preceded the onset of neurological symptoms. One culture failed to grow gonococci but the presence of Gram-negative diplococci and many pus cells in the urethral discharge and the immediate response to penicillin are strongly suggestive of gonorrhoea rather than any other form of urethritis. It may be that this is another example of an infective stimulus triggering an auto-immune mechanism. This is supported by the time sequence, with neuro- logical symptoms following 3 weeks after the pre- $\frac{2}{\frac{3}{c}}$ cipitating illness and by the finding of anti-nuclear 0 factor in the blood throughout the illness.

\section{Acknowledgments}

We wish to thank Dr A. J. Daly, Consultant Physician, for allowing us to publish details of his patient and Dr G. D. Morrison, Consultant Venereologist, for his help and advice.

\section{References}

Clarke, E., Bayliss, R.I.S. \& CoOper, R. (1954) Landry-Guillain-Barré syndrome: cardiovascular complications, $\vec{\omega}$ treatment with A.C.T.H. and cortisone. British Medical $\mathscr{W}$ Journal, 2, 1504.

Guillain, Georges, Barré, J.A. \& Strohl, A. (1916) Sur un syndrome de radiculo-névrite avec hyperalbuminose du liquide céphalo-rachidien sans réaction cellulaire. $\mathrm{Re}-\mathrm{G}$ marques sur les caractères cliniques et graphiques des $\overrightarrow{i r}$ reflexes tendineux. Bulletin de la Société de Médecine de l'Hópital de Paris, 40, 1462.

HAYMAKER, W. \& KERNOHAN, J.W. (1949) The Landry- क Guillain-Barré syndrome. A clinico pathologic report of ${ }^{\omega}$ fifty fatal cases and a critique of the literature. Medicine $\mathrm{O}$ (Baltimore), 28, 59.

MoRley, J.B. \& ReYNolds, E.H. (1966) Papilloedema and $\vec{\omega}$ the Landry-Guillain-Barré syndrome. Brain, 89, 205.

SABIN, A.B. \& ARING, C.D. (1941) Visceral lesions in infectious polyneuritis. American Journal of Pathology, 17, 469.

WiederholT, W.C., MULDER, D.W. \& LAMBERT, E.H. (1964) The Landry-Guillain-Barré-Strohl syndrome or polg radiculoneuropathy: Historical review, report on ninet seven patients, and present concepts. Mayo Clinic Procee ings, 39, 427.

\title{
Spirillum endocarditis
}

\author{
C. S. McIntosh \\ M.B., M.R.C.P.
}

P. J. VICKERS

M.B., B.S., M.R.C.S., L.R.C.P.

\author{
A. J. ISAACS \\ M.A., B.M., M.R.C.P. \\ Westminster Hospital, and Endocrine Unit, New End Hospital, London
}

\section{Summary}

A case of Spirillum endocarditis causing severe aortic regurgitation in a 26-year-old man is reported. The infection responded to treatment with oxytetracycline followed by ampicillin, but the valvular damage led to progressive left ventricular failure. The valve was replaced with a fresh nutrient homograft and the patient made a good recovery. A normal aortic valve appeared to have been infected.

\section{Introduction}

Infections with organisms of the genus Spirillum are uncommon and can be fatal. Endocarditis due to such infection is rare and occurs in the presence of valvular heart damage or in association with a severe chronic debilitating condition such as aplastic anaemia. We report a case of Spirillum endocarditis in a previously healthy young man with normal heart valves. 